\title{
Education to Theatricality: Expressive Arts as Pedagogy of Creativity
}

\author{
Gaetano Oliva $^{1}$ \\ ${ }^{1}$ Faculty of Education, Italian department, Catholic University, Milan, Italy. \\ Correspondence: Gaetano Oliva, Università Cattolica del Sacro Cuore di Milano, Facoltà di Scienze della Formazione, \\ Dipartimento di Italianistica e Comparatistica, Largo Gemelli, 1, 20123 Milano- Italy.
}

Received: February 25, 2015

doi:10.11114/ijsss.v3i3.745
Accepted: March 17, 2015

Available online: March 26, 2015

\begin{abstract}
Background, Education to Theatricality is a science that includes different of disciplines such as pedagogy, sociology, human sciences, psychology and the performing arts in general. The scientific basis of this discipline allows us to apply it in all possible contexts possible and with any individual, because it keep the man as he is in the center of its pedagogical process. One of the fundamental principles of Education to Theatricality is the construction of the actor person; the main aim is the development of creativity and imagination through a scientific training leads by the actor on himself. This science does not want to transform a man into an actor-object, molding him to product shows that are prepared just to be sold, but to enhance his individual qualities respecting his personality. The final product plays a role linked to the training process of every man, giving a different value to every different personality. Fundamental to the definition of identity and to the development of imagination and creativity is the conservation of the skill of expression, which represents the starting point, the key element for comparison with each other.

Method, This study discusses relationship between theater and education analyzing the main elements of this meeting: the birth of the theater workshop; the relationship between active pedagogy and theater pedagogy; elements of human creativity: pre-expressiveness, expressiveness, emotion, aesthetics, communication languages; the role of theatrical educator.

Conclusions, Educating means encouraging the positive growth of subjects personality, helping them to understand positive resources and to dissolve and solve problematic issues. Education to Theatricality as pedagogy uses the expressive arts into the theatre workshop for to lead the subject to path of growth and training activating the original potential skills of this person.
\end{abstract}

Keywords: Innovative Pedagogical Models, Art Education, Aesthetic Education, Early Childhood Education, Special Education, Theatre Education.

\section{Theatre and Education}

"Theatre is an efficient instrument of education because it refers to the whole person, to his deep humanity, to his consciousness of values, to his most spontaneous social skills" (Oliva, 2005: p. 234). This sentence can be considered a good synthesis of the contents of this essay about theatre as "efficient instrument of education".

First, the theatrical experience has the ability to involve the whole personality of the subject with his psychophysical aspects and with his ability to be able to create relationships with others. At the same time, a performance involves skills and resources of every single man, doing every time a precise choice of values. All these dimensions are involved in any educational process. Theatre is an instrument that is able to serve them all, so it can be considered a valuable resource for different educational projects.

This is also evident if we consider the aims of education and of theatrical experience. Indeed, "theatre and education are two realities that have a common purpose: on the one hand pedagogy focuses on the subject, allowing him to express himself; on the other hand, theatre pursues the same goal of education through activities that encourage the development of creativity and communication" (Oliva, 2005: p. 234). So theatre focuses on creativity and communication, even if it is characterized by a practice which has important techniques and an important history. So we can affirm that theatre has the same aims of educational action and it becomes an extraordinary ally of it. 
By this point of view, it is already clear that it is possible to define Education to Theatricality (Oliva, 2014: pp. 1758-1775 and pp. 1-20) as a genuine educational strategy that "does not want just to transmit knowledge but that wants to help the subject to train himself through experience and discovery. The purpose of theatrical education is "the knowledge of ourselves, of our possibilities and our limits in order to express ourselves and to communicate" (Oliva, 2005: p. 234).

\subsection{The Origins}

The origins of the theatre workshop can be found among many different events that have characterized the history of the twentieth century theatre (Cruciani, 1995). Compared to the previous century, theatre became reconciled to the personal and social life of man summarizing many different values. This new idea that theatre has of itself leads to a significant enhancement of two structural aspects: its centre is now the actor and the external goal is the creation of a communication with the viewer. This has been an actual revolution for theatrical history: "The Cultural Revolution, which featured the theatre in the twentieth century, can be compared in importance to the Copernican revolution. The actor in the twentieth century conquered a new centrality that shocked the way of thinking and playing theatre (Grotowski, 1968); in essence, the theatrical event remained the same: it always consisted of a text, a space, a set design, and of elements such as lights, music, make-up, etc. but actually everything became secondary and aimed at the staging of the man, of his thoughts, of his emotions (Oliva, 2009: p. 27).

This deep change in the theatrical process underlines immediately the reasons of the link with the educational process: emotions, thoughts and relationships of an actor are immediately a reflection and a display of his thoughts and of his relationships and offer the opportunity to work on his Ego and on his awareness. Many different men of theatre continue on this path, such as Stanislavsky, Meyerhold, Vakhtangov, Copeau, Brecht, Grotowski, Brook, Boal, Barba and many others. Their work are interwoven with the theories of the greatest education researchers of the past two centuries: Dewey, Montessori, Freinet, Maritain (Salati, Zappa, 2011, pp. 45-69). The twentieth century is, in fact, an era during which man goes in search of himself, of his identity and of the causes for his social life. Educational action and theatre, as special instrument, become an expression of personal and social needs: the man is looking for the authenticity of his own humanity, for the values that can ensure a good, positive and reconciled life.

The theatrical process meets this need because it is able to offer not only theoretical but also creative solutions to the educational path: "The laboratories [theatrical] of the twentieth century are configured as training experiences not only for the actor but also for every man: the theatre of the future laid its roots in pedagogy that becomes theatre pedagogy, far away from the institutional teaching, capable of being really creative and not mere transmission of knowledge" (Oliva, 2009: p. 27).

The laboratory uses practical actions to get a development and a harmonious growth of the person. The educator to theatricality uses a precise methodology organized in creative exercises. He uses methodological tools that come from the decomposition of the same components of theatre. Language, script, space, time, improvisation, character study, sounds and props are analysed and examined according to their social and theatrical characteristics. It is a performative language, directed by the action, with its own rules and that is taken into account in the final creative project.

\subsection{The Link with Pedagogical Theories}

New theatrical experiences with pedagogical reflection and practice, and this link arises from this new way of conceiving and living theatre. The union between theatre and education can be placed exactly in this shift of attention from the performance as ultimate aim to the centrality of the actor as protagonist of a process. The theatre becomes a place of discovery and possibilities, a space where imagination and creativity can freely express themselves. It meets with pedagogy because it puts man in the middle and gives him voice, because it is able to recover every single man with his own personality and his own expressiveness and help him to grow through an individual process that is however inserted into a group project. The theatrical laboratory starts with the encounter of these two realities (Oliva, 2005: p. 231).

Theatre, focusing properly on the experience-laboratory of the actor-person in connection with the other actors-persons, coincides with the educational path of an individual and of a group. All this happens even thanks to the development of instruments such as imagination, improvisation and creativity which are typical of theatrical work: these instruments become the vehicle for the discovery and the management of emotions, of feelings and of relationships; in wider terms, of the entire inner world of the individual that can discover his identity, that trains, grows and take care of himself.

This way of thinking and acting can be matched with the pedagogical studies of some researchers such as John Dewey (1859-1952), American philosopher and teacher. He highlights for the first time, in the field of education, the 
importance of living an experience that becomes more important than the cognitive contents of the experience itself. Every man educates himself within the experiential process inserted into the social fabric.

Even the Italian Maria Montessori (1870-1952) presents some important points of contact between her pedagogical analysis and the innovations of the twentieth century theatre. Montessori talks about an education of liberation, through which every child must be returned to himself, to his nature. And from this new starting point, that becomes the centre of her interest, the laboratory gets its sense and justifies its existence. Foremost, the theatre laboratory should be a special place, a protected environment in which the central element is no longer the final performance, but the process, the path of discoveries and training which every human being performs and lives in first person. So experimentation becomes crucial. Exploration, comparison and conflict with other realities are really important, so every man can live theatre with all his being, starting from that training that is put into practice (Oliva, 2005: p. 233).

Therefore theatre becomes a protected place where the subject may, in the absence of judgement, investigate his Ego, to prove himself in relation to this Ego and to others. He can improvise new scenarios and experience new personal freedoms mediating between its intimacy and its sociality to reach a new form within his personal growth. The thought of these two educators, in a nutshell, clearly show how pedagogy and theatre laboratory intertwine each other in a very profitable relation. In summary: "The balance between these two dimensions, the pedagogical and the theatrical one, becomes indispensable in a laboratory of education to theatricality that wants to be a place where physical and psychic awareness and expressive skill of a new-found identity can develop harmoniously. The training of the actor-person is not aimed to the transformation of a man into "another person", but aims to enhance his quality always respecting his personality"(Oliva, 2005: p. 234).

We can refer to a sort of "active education" because it helps the single person to develop attitudes that allows him to know how to act appropriately in new social situations. In other words, the theatre laboratory wants to safeguard, with different modalities and goals, the dignity of the person and the validity of the society to which he belongs.

\section{Education to Theatricality: An Interdisciplinary Science}

A kind of theatre that is intertwined with the pedagogical theories and that creates an educational experience becomes a place where there is a constant exchange with human sciences. Education to Theatricality is a science that is composed of disciplines such as pedagogy, sociology, social sciences, psychology and performance arts in general. The scientific nature of this discipline allows to apply it in all contexts and with any subject, because the focus of its pedagogical process is the simple human being, who is not considered as man who is necessarily able to do something.

Interdisciplinarity of Education to Theatricality is therefore an immediate consequence of the fact that education and theatrical experience regard the whole personality of every human being in all his dimensions. This is not a theoretic relation and it puts on the line/ on stage a concrete free and creative experience. Several human (individual and social) disciplines are invited to take part to this laboratory, as well as it can regard various subjects and different contexts. Any person has something to say, or rather, has a lot to express: he just needs the willingness to get involved and to unleash creativity.

Education to Theatricality is trying to define into strictly scientific terms the process that leads to the development of a creative act. The objective of Education to Theatricality is to educate people through the expressive arts in order to develop the creativeness and the personal expressiveness of each individual. Education to Theatricality was started in Italy in the last decade of the twentieth century. It develops and elaborates the studies, the experiences and the ideas developed by the directors - Stalislavski, Mejerchol'd, Vachtangov, Copeau, Brecht - by some theatrical theorists of such as Grotowski, Brook, Boal Barba, and by the Italian experience of the "Animazione teatrale". These artistic experiences are reread in relationship to the studies of the pedagogic and psychological studies of the eighteenth and fourteenth centuries (Dewey, Montessori, Freinet, Maritain).

Education to Theatricality, which find its psycho-pedagogical basis in the concept of art as a vehicle defined by Grotowski, is education for creativity and it represents a precious opportunity for anyone to affirm their identity, claiming the value of the expressive arts as a vehicle for overcoming the differences and as an actual element of integration. Education to Theatricality develops the theory of the actor-person (Oliva, 1999: p. 93). It is possible to summarize this idea with the I-AM's scheme. 
Table 1. I-AM’s Scheme (Oliva, 1999: p. 98)

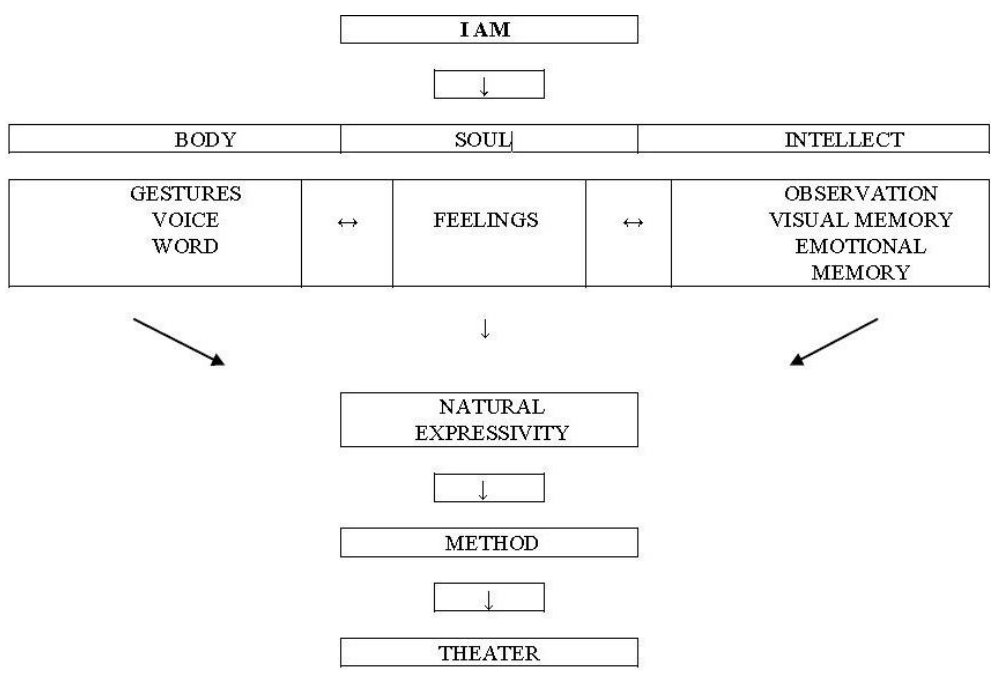

The starting point, therefore, is to keep that natural expression that everyone retains within himself; you can define it pre-expressivity. In the construction of the person-actor, the purpose is just to develop the person in its organic structure, starting from his or her nature and essence, through a work on the Ego that will allow this person to reach his or her natural, physical, emotional and intellectual pre-expressivity. The spontaneity that man manifests through these components will be addressed towards theatrical methodology so as to develop individual creativity. Man is a relational being, therefore it is necessary that he carries out this individual process within a group. The encounter and the comparison with other people allow him to enter in a dimension of greater understanding of himself and of the others. In fact, thanks to the verbal and nonverbal responses to the behavior of others, the man increases his knowledge and it is placed in a state of discovery. In addition, this situation helps him to be sensitive about the management of space and time. In summary, pupils are accompanied in the conquest of their I-AM (Oliva, 2014, p. 1762). The physical and mental space where I-AM process formative develops is the theatrical laboratory.

\section{Laboratory as a Methodological Instrument}

The theatrical art becomes an educational instrument with the laboratory. This is a place of experimentation and growth. The theatre laboratory has a strong pedagogical value and offers an important contribution in the educational process. During training that every person performs on itself, the laboratory leads to learn to "pull out" what "screams inside", knowing and controlling energy, accepting what at first was suppressed or repressed. Theatre, experienced as a laboratory, allows to expand the range of expertise and permits to experience different life situations which are qualitatively different from the usual ones. It can contribute to a redefinition of the Ego, of the world, of the others. Theatre, in this sense, means to reconsider our past: live again anxieties, revisit certain behaviours or situations, not to remove them, but to be aware of being grown up and becoming able to recognize their positivity.

The theatre workshop is based on three dimensions. First, the laboratory experience is a physical action that involves the whole body and the voice of the actor-person. The gestures, the shape and the movement express or hide inner resonances. Voice and words are included into this corporality, in fact, it confirms, clarifies, emphasizes or denies the truth of the positions of the body; at the same time there is also an inverse relationship: the body weakens or gives strength to the truth of words.

A second dimension is creativity. By definition, the theatre laboratory is a place where the actor-person can and should give free rein to his imagination, even because that is not always possible in everyday life. In fact, in this particular place every person develops his own energy, that condenses into new creations which open horizons unknown to his knowledge.

Lastly also the social dimension is intertwined with these two elements. The body is always in relation with what surrounds him: other bodies, objects, environment and so on. So the experience of the actor-person is modulated in comparison, which can be more or less confrontational, with the sphere of living together. These tools "lived" in the laboratory determine some dynamics which highlight the educational and pedagogical value of such experience.

First dynamic is a sort of "suspension". During the workshop, the daily routine is temporally suspended and we create a dimension protected by the usual conditioning and judgements that every person has to normally face. This particular characteristic produces confidence and the right environment to develop an educational process and educational 
relationships. This suspension helps every subject to explore his inner part, but also to investigate the context and the social and personal resources that he has to deployed. This possibility is the actual chance for the involved players to train themselves.

The step of exploration can be considered the starting point of the "construction" step. The process of a laboratory may, in fact, leads every actor-person or the whole group to recognize a new kind of personal attitude, of psychic or social behaviour that has been built in the workshop and that becomes part of a consolidated educational heritage. This innovation expresses the actual possibility of change that every educational process should bring out and, step by step, lead to fulfilment. This brief description can be explained with three intertwined levels within the experience workshop (Oliva, 2005: p. 237):

- individual level: the actor-person puts on the line precise skills to be able to stay on the stage or to handle a confrontation with an audience, through the dramatic monologue, that is a medium of contact with the Ego typical of theatre; he has to use these particular skills in everyday life, getting a greater fulfilment both from himself, and from others;

- Relational level: at this step the individual subject experiences the dialogue, that is a psycho-physical relationship with a partner on the stage. To manage to establish an emotional contact with the partner it is necessary to develop others human faculties, such as precision and self-control;

- Group level: at this late step the single person lives and experiences in and with a group.

In the didactic situation of the theatre workshop, special forces develop between the students, the teacher and the group: their creative existences come into a dynamic relationship. The fulfilment of the Ego is created by this comparison with the others. An interaction that can not take place without dialogue and experimentation.

\section{Pre-Expressivity}

Every person has to communicate, but not every person is always aware of his expressive status.Education to Theatricality starts by the idea that each subject has an own natural pre-expressivity that characterizes him in a particular way, even if he is not aware of this. Becoming aware means to discover our Ego and this implies the desire and intention to get deeply involved.

"The concept of pre-expressivity, then, is useful because it is thought in relation to the actor, who is a person who uses an extra-daily technique for his body, in a situation of organized representation; it is linked to the single human being and accompanies it throughout its path, taking different shapes and changing with it. In this sense, it is not correct to refer to man and pre-expressivity as two distinct realities: the two terms are mutually interwoven" (Oliva, 2005: p. 235).

The human being does not fully reveals itself if it does not discover and enhance its pre-expressivity. Development of imagination and of creativity is therefore the main goal to achieve to enhance the personal qualities of the involved subjects. This aim can be reached by following the synthetic formula: "pre-expressivity + methodology $=$ development of individual creativity" (Oliva, 1999: p. 89).

In this formula, the word methodology contained also the expertise to create improvisations. This instrument has an educational purpose even before than a theatrical one, because it has a huge introspective strength. It is able to let emerge countless personal elements (emotions, memories, insights, feelings) otherwise hidden and submerged but that influence personality and the action of the subject .

\section{The Emotion}

The experience of feeling emotions is not a choice of the individual: the emotion occurs in the psychic world of the person because of happening external of it, but also because of inner dynamics that are not easily recognizable. The psychologist Ricci Bitti has written: "The emotion should be considered a psychological construct in which different components are involved. A cognitive part aimed at the assessment of the situation-stimulus that causes the emotion; an element of physiological activation determined by the intervention of the autonomic nervous system; an expressive-motor part; a motivational part, linked to the intentions and to the tendency to act / react; a subjective part that is the feeling experienced by the individual. All these parts are interdependent and participate in determining the emotional experience. (Ricci Bitti, 2008: p.77).

This definition helps to understand that emotion is a very complex phenomenon which is woven throughout the life of every human being. There are no areas in which a human being feels no emotions: there can be situations in which emotions are hidden or showed; they can be in harmony with the actions that a man does, or they can be in opposition to these actions making them difficult or impossible. Sometimes the subject recognizes his emotions and is able to manage them profitably, sometimes, however, the subject is overwhelmed and the consequences are not always positive for his lives; finally, sometimes the subject censor his emotions, because he does not want or is not able to accept them. The 
complexity of this experience is enhanced by the fact that emotions are always inner activities in mutual exchange with the body: the emotion lives inside the body and influences it, but at the same time the body affects emotions.

The psychologist Ricci Bitti has written: "In the vast majority of cases, the emotions are expressed and communicated not only by spoken language, but even through a series of non-verbal signals that involve face, tone of voice, boody and so on. These verbal and non-verbal signals (in a so different way from subject to subject and from culture to culture) that denote emotions can be controlled, disguised, inhibited or even highlighted depending on the circumstances". (Ricci Bitti, 2008, 78).

It is evident that an education to emotions is necessary for the existence of every human being. This education often takes the shape of a real emotional literacy that starts first from a basic question that should never be taken for granted: what are the names that I can give to what I live and feel inside myself now? Being able to tell emotions with words rich and full of meaning is the first step to be able to live with them in a positive and reconciled way. Emotions are, in fact, a complex world that can be even ambiguous and contradictory, that can offer gusto but also disgust to life. They can offer a huge benefit to cognitive function (emotional intelligence) or can inhibit them powerfully and, finally, they can be invaluable resources to human relations but also causes of depressions and autistic closures.

Health and individual well-being depend largely on the control and on the regulation of emotions. The ability to control, express, live and feel emotions is a skill that not all people have in the same extent and that, in certain circumstances, may be particularly important to develop or acquire. We have the "emotional intelligence". This term is referred to various factors that compose the human intelligence, to an emotional skill that allows many human beings to be able to live successfully, to live better, and often longer. This emotional skill is expressed in some particular areas, such as:

"l. knowledge of emotions, that is the ability to be self-aware of the emotional experiences and to be able to observe the Ego;

2. control and regulation of emotions (pertinence of expression and of the emotional experiences, being able to avoid the so-called "emotional kidnapping", that means to be dominated by emotions);

3. the ability to be able to self-motivate (preparation of plans and goals, ability to tolerate frustration and to postpone gratification);

4. recognition of emotions of others (empathy);

5. the management of social relations between individuals and into the group (leadership skill, negotiation, etc.)" (Ricci Bitti, 2008: p. 78).

It is urgent to educate people to recognize and manage emotions, even because in today's world, the society and in particular the trade industry, are very interested in the emotions of the human being. It is important to help people to recognize emotions in their complexity, so they can develop a personal balance without forgetting values, or the real substance of their own lives and the strength of their choices.

Through a process that allows every person to work on the relationship with the Ego and the others, the theatre workshop allows to use resources in order to be able to perceive emotional knots, inner conflicts, communication blocks and to handle with them. The theatrical workshop in relation to another human being becomes an instrument to tolerate strong emotions, to project them outside, to control them, live them and share them at a distance, until it becomes possible to reintroduce them inside ourselves. We can not always avoid the frustrations but we can learn to tolerate them, and theatrical activity can offer available alternatives to learn to dominate negative moods. The theatrical activity helps the human being to become aware of body language and be aware of behaviour, emotions and thoughts. This is the first step to have a genuine dialogue with our Ego and succeed in reaching full growth, acceptance and self-awareness.

\section{Education to Beauty}

Art has to reveal the beauty of reality, clearing it from the impurities that dull it. "Theatre must never forget his artistic nature: in addition to recover the subject who has a need, it must especially communicate the aesthetic sense of art itself; theatre is art and the person who approaches it must, first of all, look for imagination and creativity inside its own Ego" (Oliva, 2005: p. 238).

A human being who glean from experiences, wants to rediscover freely the most authentic dimensions of existence, that testifying a wonderful symphony between the good, the beauty and the truth. The creativity, the attention to relationships and emotions, the free and harmonic expression of body in tune with the soul encourage the discovery of the concept of beauty.

Art is a witness of this idea: every artistic event escapes the dimension of the need but looks for the dimension of fun and free gift. It does not mean to learn new gestures, to make mind more elastic reciting a part from memory, but rather, to introject a new existential category eradicated from consumption, from empty show, from the cannibalistic need to 
have immediately everything. Theatre becomes an important space-time to become aware that everywhere, even in prison, even in our Ego, although we are criminals or disabled, you can find something beautiful. This awareness is reflected in the acquisition of a new interpretive tool of Ego and of the world. (Oliva, 2011: p. 211).

The theatrical experience lived during the "process" leads to a growth of freedom and of personal creativity. The more the subject is growing in his human training, the more he discovers that is an artist and "produces" art revealing the beauty of himself and of life, discovering the beautiful everywhere and in every person.

\section{The Role of Theatrical Educator}

A teacher who plays the role of theatrical educator and who wants to direct this kind of project (Santerini, Triani, 2007) has to proceed to an accumulation of images, suggesting similarities of behaviours, stimulating logic thoughts, and sometimes favouring poetic insights (Musaio, 2007). It is often necessary that he participates in the game of the imagination personally, to stir some inhibitions, to dissolve some reserves, to provide some examples, to show himself and to feel personally involved in the creative process with all his personal fantastic baggage. The role of the adult, in this sense, is in many ways similar to that which is entrusted to the director of a play, that is, to who is responsible for the final decisions.

The adult, in fact, has different tasks: determining what direction of research the work has to take, determining the sequence and consistency of the different steps of the creative process and indicating any changes in the program. The rehearsals of a play are so called because it is inherent in them the possibility of error, in fact, their function is to investigate different modalities, to search for the solution that is most satisfactory and suitable in relation to the economy of the whole representation. It is important to fix the free improvisations that will mark the first step of the work in definitively agreed situations, commonly accepted ideas, precise lines, elements of a real theatrical dialogue.

In addition, the leader of the laboratory is responsible for directing, containing and leading the group towards a full acceptance of the other (Triani, 2002). This subject is configured necessarily as an actor-educator and should be able to manage professionally theatrical and educational skills. In his work he has to modulate the experiences and the expression of the students so the choral dimension of the creative process should allow the development of the individual and of the group.

"The teacher, in a training course, become an educator and it is defined an educator to theatricality. He has the task of leading and supporting, proposing stimuli, offering suggestions, reiterating comments and questions rather than providing answers, information and exclusively theoretical concepts. It is appropriate that this teacher does not arise as a role model, but knows how to become a reference point. The educator must know the methods of "Animazione Teatrale" (Oliva, 2010a, pp. 168-196) knowing how to become an important element for the creation of the group ("Animazione Teatrale" is a cultural movement developed in Italy in the sixties and seventies, particularly with children and young people, and from which a number of practices, techniques and methods are applied in the leisure and education). Then, it is important that the teacher learn and understand how to stimulate the expressive reaction of each student. The educator, once caught in the students the willingness to express themselves, has to be able to step aside so to not overlap with him and to not stifle his creativity" (Oliva, 2009: p. 42).

During a theatre workshop, the teacher must be at the same time: a theatre director, an educator and an entertainer. Only the skilful interweaving of these three skills allows the individual and the group to live a fruitful pedagogical process inside of the theatrical experience.

The maieutics method is common to all these dimensions: the teacher of the laboratory must have confidence in the potential of individuals and must know how to build the conditions that allow each person and the whole group to let emerge the important elements, emotions, imaginations, memories, actions, events. The cleverness of the director who, at this point, is in effect also an educator, is precisely to create that emotional and communicative dimension in which each participant can feel free to express himself. The teacher of the theatre workshop should encourage without binding; lead without directing; stimulate without filling with content; offer security without imposing his ideas: this balance requires experienced skills and human qualities developed by a continuous personal work. From a strictly pedagogical point of view: "[...] The particular characteristics required to an educator to theatricality start from his personal dimension: he must be a mature person who is not afraid to out himself on the line. He has to have communicative skills and to possess a sort of intellectual flexibility that allows him to adapt to all situations. Above all, he has to be motivated and has a playful and positive style in his work method [...]. It is important that he is able to wisely manage the relationships, focusing on the individual without neglecting the group dimension: it is important to be a good observer, in order to understand the characteristics and problems of different participants. Anyway he must be able to accept unconditionally each student and have the ability to put his confidence in each one [...].It is essential to also have organizational skills, because he has also to be able to plan an educational intervention appropriated to different contexts, handle with different realities and situations" (Oliva, 2010a: p. 264). 
As regards the knowledge of theatre pedagogy, the leader of the laboratory: Should not necessary be a professional actor, but must have good expertise in both theory and practice of theatre; we cannot think that the leader of a theatre workshop has never personally experienced the same process that he propose to others. It is also necessary that he possesses a good knowledge of the history of theatre, so he can stimulate curiosity about theatre culture in his students and become an actual promoter [...]. An educator to theatricality should be able to manage the whole theatrical art, so he has to develop good skills in different fields, such as movement, music, scenes or lighting techniques.

It is worthwhile to note that the master-disciple relationship is affective-relational. A relationship without this depth would not allow the activation of all the dimensions described above. This affective relatedness is the actual educational love.

Talking about educational relationship means talking about educational love. In this kind of love there is the coincidence of two distinct elements: unity inside diversity. In fact, true love brings out single personality within their differences. Love has some features:

- Protection. True love is always there for the others, it protects but let free other human being to experiment their own individuality.

- Distinction. True love recognizes other's need.

- Rationality. True love should never be separated from reason. Degenerations are due to a prevalence of irrationality.

- Altruism (Oblatività). It is typical of parents' love: an unselfish and sympathetic love (Oliva, 2009: p. 41).

Flexibility, adaptability and elasticity are qualities that every educator must necessarily possess in order to be able to adjust his educational offer to the environment and to the people he works with. To make sure that personal creative skills can be developed by theatrical education, it is important to propose adequate instruments and contents, therefore it is essential to plan a theatrical educational project with specific goals and aims.

\section{Conclusion: Theatrical Activity as Pedagogy of Creativity}

Educating means encouraging the positive growth of subjects personality, helping them to understand positive resources and to dissolve and solve problematic issues. Educating means allowing every single person to reach a more serene and mature humanity, making it able to realize itself in relationship with others and with the context. Creativity is one of the most important resources for this maturation process because it is a bridge between the Ego and the Ego in relation to others. Educating therefore also means educating to creativity, releasing the person from any blockages and allowing a continuous development, thus removing both cultural and psychic obstacles .

At the base of education to creativity there is the confidence in the human being, seen as able to take upon himself the responsibility of his actions. The subject has the chance to assert his individuality through the use of a variety of languages, both verbal and non-verbal (Oliva, 2005: p. 22). The theatre workshop is therefore able to lead the subject to path of growth and training, even of his imaginative sphere, thus activating the original potential skills of this person.

\subsection{Conclusive Note}

Education to Theatricality as pedagogical and artistic research is experienced by almost twenty years in Italy in laboratories and projects organized in collaboration with universities, schools, theaters, educational centers, cultural centers, educational and social services, associations. The present theoretical writing - Education to Theatricality: expressive arts as pedagogy of creativity - synthetically introduces the fundamental elements of the theory. Over the years the theory was investigated through congresses, studies and publications (for example: Pilotto, 2006. Pilotto 2007. Oliva, 2005. Oliva, 2010b. Salati \& Zappa, 2011). The study is developed by different research bodies, amongst others: the professorship of Theater-Education and Dramaturgy (Faculty of Education Catholic university in Milano, Brescia and Piacenza - Italy), masters Creativeness and personal growth through the theatricality (Faculty of Psychology and Faculty of Education of the Catholic university, Milano - Italy) and masters "Actions and Pedagogic Interactions through the Narration and the Education to Theatricality" (Faculty of Education of the Catholic university, Milano - Italy), Center of Theatrical Search "Theater-Education (CRT Centro di Ricerca Teatrale "Teatro-Educazione", Fagnano Olona - Italy).

\section{References}

Cruciani, F. (1995). Registi pedagoghi e comunità teatrali del '900. Roma: E \& A editori associati.

Grotowski, J. \& Schechner, R. “ Chwat, J. (1968). An Interview with Grotowski: The MIT Press, Cambridge.

Grotowski, J. (1968). Towards a Poor Theatre: Odin Teatrets Forlag, Denmark.

Grotowski, J. (1970). Per un teatro povero. Roma: Bulzoni.

Musaio, M. (2007). Pedagogia del bello, suggestioni e percorsi educativi. Milano: Franco Angeli. 
Oliva, G. (1999). Il laboratorio teatrale. Milano: LED.

Oliva, G. (2005). Educazione alla teatralità e formazione. Dai fondamenti del movimento creativo alla form-a-zione (Education to Theatricality and education. The bases of the creative movement and its use in education). Milano: LED.

Oliva, G. (2010a). L'Educazione alla Teatralità e il gioco drammatico, Arona, XY.IT Editore.

Oliva, G. (2010b). La musica nella formazione della persona (The music in the education). Arona: XY.IT Editore.

Oliva, G. (2011). L'Educazione alla Teatralità: il Progetto Uomo. Text inside Cariboni C., Oliva G., Pessina A. (2011), Il mio amore fragile. Storia di Francesco. Arona: Editore XY.IT.

Oliva, G. (2014). Education to Theatricality inside Secondary School, Art and Body, CE Creative Education (USA), Vol.5 No.19, November 2014, 1758-1775.http://dx.doi.org/10.4236/ce.2014.519197

Oliva, G. (2014). Gaetano Oliva, Education to Theatricality: Creative Movement as a Training Model", Global Journal of HUMAN-SOCIAL SCIENCE: G Linguistics \& Education, Global Journals Inc. (USA), Volume 14 Issue 9, 2014, $1-20$.

Pilotto, S. (2006). Scuola, teatro e danza. Trasversalità delle arti del corpo nella didattica scolastica, (School, theater and dance. Interdisciplinaryof the arts of the body in the scholastic didactics). Atti del Convegno (Congressional records) 17 e 18 febbraio 2005, Milano: I.S.U..

Pilotto, S. (2007). Creatività e crescita personale attraverso l'educazione alla arti: danza, teatro, musica, arti visive. Idee, percorsi, metodi per l'esperienza pedagogica dell'arte nella formazione della persona (Creativeness and personal growth through arts education: dance, theater, music, visual arts. Ideas and methods for the pedagogic experience of the art in person's education), Atti del Convegno (Congressional records) 13 e 14 febbraio 2006. Piacenza: L.I.R.

Ricci Bitti, P. E. (2008). Arti-terapie e regolazione emozionale. Text inside Di Rago, R. (2008) Emozionalità e teatro. Di pancia, di cuore, di testa. Milano: Franco Angeli.

Salati, E. M. \& Zappa, C. (2011). La pedagogia della maschera. Educazione alla teatralità nella scuola (Mask’s pedagogy. Education to Theatricality in the school). Arona: XY.IT Editore.

Santerini, M. \& Triani P. (2007). Pedagogia sociale per educatori. Milano: Educatt.

Triani, P. (2002). Sulle Tracce del Metodo. Educatore Professionale e Cultura Metodologica. Milano: I.S.U. Università Cattolica.

\section{$(\mathrm{cc}) \mathrm{BY}$}

This work is licensed under a Creative Commons Attribution 3.0 License. 